\title{
Livros
}

\section{O desafio da esquizofrenia}

Editado por Itiro Shirakawa, Ana Cristina Chaves e Jair J. Mari. 1998. São Paulo:Lemos Editorial \&Gráficos Ltda, 279 páginas. ISBN 85-7450-002-X

A esquizofrenia é uma síndrome polimorfa que incide com maior freqüência entre os adultos jovens. Com um curso geralmente cronificante, implica na reminiscência de sintomas psicóticos, no deficiente ajuste e desempenho social e na intensa utilização de serviços hospitalares, ambulatoriais e de atendimento emergencial. A esquizofrenia não é o mais prevalente transtorno mental, quan-

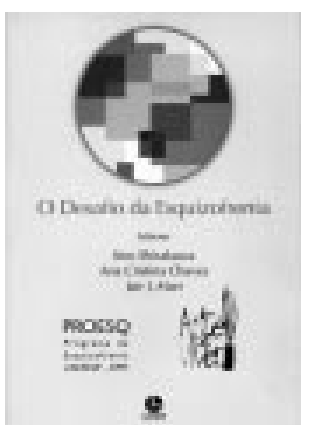
do por exemplo é comparado ao alcoolismo e dependências químicas ou transtornos afetivos ou de ansiedade, porém, numericamente é significativa entre a população usuária de serviços de saúde mental. Os custos que decorrem da assistência ao paciente, os que resultam da cessação de uma vida produtiva e independente, e os gerados pelo impacto familiar são imensos, alcançando frações não desprezíveis do PIB (Produto Interno Bruto) dos países industrializados.

No Brasil os cálculos dos custos da esquizofrenia ainda são incipientes e incompletos. Seguramente, se as nossas autoridades responsáveis pela dotação orçamentária os conhecessem, seriam mais criteriosos no incentivo à implantação de uma rede de assistência mais eficiente ao paciente esquizofrênico e à sua família. Neste contexto, é muito bem-vinda uma obra intitulada "O Desafio da Esquizofrenia", capaz de colocar ao alcance do profissional médico e de outras áreas de saúde mental envolvidas com a assistência ao paciente esquizofrênico uma ampla palheta de informações úteis e indispensáveis para a tomada de decisões terapêuticas e para o planejamento de programas de atendimento.

O livro é uma iniciativa do Proesq (Programa de Esquizofrenia da Unifesp-EPM), um serviço de pesquisa e assistência para pacientes esquizofrênicos na cidade de São Paulo, e reúne a contribuição de 18 autores, na maioria pós-graduandos da disciplina de psiquiatria da Unifesp. Com a edição de Itiro Shirakawa, seguramente um dos profissionais mais experientes no manejo terapêutico de esquizofrênicos em nosso meio, Jair Mari, um destacado pesquisador que se tem empenhado em mudar o perfil da pós-graduação no Brasil, e Ana Cristina Chaves, coordenadora do Proesq, é apresentado um amplo enfoque da síndrome esquizofrênica. O livro foi subdividido em quatro grandes áreas de estudo: $1^{\mathrm{a}}$ ) critérios diagnósticos e estudos etiológicos; $2^{a}$ ) estudos de prognóstico; $3^{a}$ ) intervenções terapêuticas e $4^{\mathrm{a}}$ ) aspectos culturais. Para finalizar, Itiro Shirakawa, em um capítulo apresentado à parte, sob o título "Manejo Terapêutico", discorre, com a informalidade que lhe é própria, sobre sua prática terapêutica. Ao longo de 16 capítulos são revisadas mais de 800 referências. Um trabalho valioso, dada a avalanche de informações e referências existentes na literatura especializada sobre o assunto.

Inicia-se com a descrição da evolução dos critérios diagnósticos em esquizofrenia, passando em revista o seu percurso a partir dos autores clássicos até os critérios atuais do DSM-IV e CID-10. O capítulo referente à epidemiologia é uma retomada conceitual da metodologia de investigação epidemiológica, na medida em que discute de forma detalhada os procedimentos e as dificuldades para a investigação sobre a prevalência e incidência da esquizofrenia nas populações. A genética é discutida com semelhante rigor, pois seu autor se mostra preocupado em conduzir o leitor por um assunto bastante específico e geralmente pouco familiar. A discussão do papel do neurodesenvolvimento, imprescindível para uma conceituação mais ampla, no sentido de uma anomalia estrutural do SNC, já é mais sucinta, limitando-se à apresentação de dados de pesquisa.

O segundo bloco, que concerne os estudos de prognóstico, é um dos pontos altos do livro, pois seus autores se remetem a pesquisas originais sobre o assunto, realizadas no nosso país. Como a quase totalidade de informações sobre o prognóstico da esquizofrenia provém da literatura internacional, sendo portanto obtidas de campos de pesquisa bastante distintos dos da nossa realidade, os dados aqui apresentados tornam-se particularmente atraentes. É o caso, por exemplo, do estudo sobre o curso e prognóstico após a hospitalização, em que uma coorte de pacientes psicóticos são reavaliados após dois anos, focalizando as variáveis de estudo de psicopatologia e ajustamento social, além de outras variáveis clínicas. Outro estudo mostra as diferenças entre os sexos no início, na evolução e no prognóstico, discutindo as possíveis determinantes de um pior prognóstico para o sexo masculino. Ainda em outro estudo é discutida a correlação entre sintomatologia (psicopatologia) e a "incapacitação social", mostrando que, além de o sexo masculino encontrar mais dificuldades nos relacionamentos sociais, a presença de sintomas deficitários, ou negativos, também intervem no desempenho social. Finalmente, para encerrar este bloco, é des- 
crita a depressão em pacientes esquizofrênicos, uma ocorrência não rara e que se confunde, com facilidade, com os sintomas negativos ou os possíveis efeitos colaterais das medicações antipsicóticas.

O terceiro bloco, o das intervenções terapêuticas, abre com um capítulo sucinto, apresentando as bases do tratamento farmacológico. Dada a importância do assunto - uma vez que hoje pode-se contabilizar os maiores avanços na melhora da qualidade de vida do esquizofrênico ao nosso melhor conhecimento das potencialidades e dos limites da ação dos diversos agentes antipsicóticos - o tema mereceria um tratamento mais abrangente, se aprofundando, por exemplo, nas diferentes estratégias de uso dos neurolépticos nos distintos momentos da doença. Já o enfoque dado à psicoterapia - foram destinados dois capítulos ao assunto, o das terapias individuais e outro para as grupais - é primoroso, visto que seus autores conseguem apresentar um assunto tão polêmico, como é o da psicoterapia em psicóticos, com objetividade e clareza. Ao citar Katz, "Hoje, uma abordagem psicoterápica que negue a relevância dos componentes orgânicos para a esquizofrenia é tão obtusa quanto uma visão biomédica, que simplifica a esquizofrenia em termos de uma doença para a qual apenas uma droga apropriada deva ser prescrita, e que ignore o papel desempenhado pelas experiências de vida", assumem claramente a sua necessidade e viabilidade mediante o uso de objetivos e técnicas bem definidas. Da mesma forma, os propósitos e as técnicas da terapia ocupacional - geralmente fala-se muito em T.O., mas sabe-se pouco sobre seus recursos e objetivos - são apresentados assentados no eixo tratamento-reabilitação. $\mathrm{O}$ enfoque dado à terapia familiar é original e elegante: mediante a realização de uma metanálise, os autores agruparam seis estudos de intervenção familiar, abrangendo um total de 350 casos, concluindo sobre a eficácia desta modalidade na prevenção de recaídas.

A apreciação da esquizofrenia no contexto cultural não é habitual nos livros do gênero, ou melhor, é merecedora de poucas citações. Aqui, no quarto bloco, o tema merece um tratamento amplo e esclarecedor. Na cuidadosa revisão sobre esquizofrenia e cultura, são apresentados ao leitor trabalhos que investigam as diferenças que há na manifestação da esquizofrenia entre as diferentes culturas. Assim, é de conhecimento que a esquizofrenia tem diferentes desfechos nos países mais ou menos desenvolvidos, pois acredita-se que haveria fatores precipitantes ou agravantes de um lado e protetores ou atenuantes de outro, que explicariam as diferenças nas apresentações clínicas. Isto, evidentemente, levanta questões sobre sua dinâmica e interação ambiental. Em um outro capítulo, este já voltado para o microambiente familiar, fala-se "das representações de doença pelos familiares, das nomeações e dos conceitos constituídos ao longo da experiência com o familiar doente", e de como, "ao não fixarem um único conceito para a doença, os familiares desenvolvem uma estratégia para lidar com ela". De uma forma mais ampla, no último capítulo, é apresentado um trabalho que investiga um propósito semelhante, ou seja, de como uma comunidade, no caso a República do Cabo Verde, concebe os indivíduos com esquizofrenia e quais recursos dispõem para lidar com essas pessoas.

Mas, não obstante a sua elevada qualidade, há ressalvas a fazer. Assim, ocorre por exemplo indagar se não há falta de alguns enfoques bastante úteis na monitorização e avaliação mais fina de cada caso. Para isso é imprescindível uma discussão mais fina da psicopatologia, um enfoque que infelizmente é cada vez mais sacrificado, na medida em que se universaliza o uso de escalas e instrumentos de avaliação que, embora tenham contribuído de forma inegável para uma aproximação conceitual e aberto a possibilidade da pesquisa em psiquiatria, são de pouca utilidade para a prática clínica do dia-a-dia. Muito se beneficia aquele que conhece os autores clássicos, que com invejável depuração de detalhes conseguiram descrever a realidade vivida pelos seus pacientes. Maior destaque mereceria também a descrição da história natural da esquizofrenia, seus pródromos, suas primeiras manifestações clínicas, a sua evolução em surtos agudos intercalados na maioria das vezes por períodos de estabilização e seus estágios de cronificação. Muitas dessas informações, que estão nas "entrelinhas" ou espalhadas ao longo dos diferentes capítulos, mereceriam um capítulo próprio. Outra contribuição que faz falta, esta já recente e atual, concerne o estudo na neuropsicologia e neuroimagem, um enfoque que, apesar de não ter encontrado um lugar demarcado na clínica assistencial, é uma vertente importante da pesquisa que talvez, no futuro, venha cumprir a tarefa de integrar áreas hoje ainda distantes, como a da farmacologia e da clínica. Mas incluir ou excluir este ou aquele enfoque de um assunto tão amplo como a esquizofrenia é a "angústia de quem faz", pois é impossível falar de tudo, sob pena de superficializar o conteúdo ou, quem sabe, nunca finalizar a tarefa.

Wulf H. Dittmar

São Paulo - SP

\section{Luto: estudos sobre a perda na vida adulta}

Por Colin Murray Parkes. 1998. São Paulo:Summus Editorial. 291 páginas. ISBN 85-323-0581-4

O lançamento do livro, Luto: estudos sobre a perda na vida adulta, pela primeira vez traduzido para o português, apresenta Colin Murray Parkes, psiquiatra britânico que vem se dedicando a estudar as questões que envolvem o luto. Seu trabalho teve início no final da década de 1950 em estreita colaboração com John Bowlby. Parkes fez parte da equipe de pesquisadores no 
Instituto Tavistock de Relações Humanas até 1992, ano da morte de Bowlby. O livro de Parkes nos ajuda a identificar e entender as raízes do pesar, os danos causados pelo luto e as maneiras de ajudar os enlutados a emergir desse sofrimento. Apresenta de forma atualizada as questões presentes na experiência de perda por morte, além de apontar de maneira mais resumida para outros tipos de perda, como o divórcio, o desemprego, a esterilidade/infertilidade e as perdas envolvidas na recuperação de um câncer.

Os exemplos e as referências da literatura permitem ao leitor compreender os diferentes caminhos da experiência de ter um vínculo rompido por morte e as conseqüências dessa experiência, em âmbito somático, social, emocional e cultural. O luto é entendido por Parkes como uma importante transição psicossocial, com impacto em todas as áreas de influência humana. Outra importância do livro é que seu conteúdo é acessível a médicos, enfermeiros, psicólogos, assistentes sociais e àqueles que têm contato com pessoas enlutadas. A obra tem como objetivo principal oferecer um entendimento abrangente sobre o luto e seu processo, permitindo que vários profissionais possam prestar uma ajuda mais efetiva.

Os primeiros capítulos, basicamente conceituais, expõem o luto numa visão muito próxima ao modelo de doença, em que Parkes apresenta o luto como evento traumático, sua relação com a doença mental, e nos mostra as mudanças de atitude que ocorrem na sociedade quando morre uma pessoa. Neste sentido, Parkes ressalta o importante papel da pesquisa, a fim de compreender melhor os meios pelos quais o luto pode levar a distúrbios psiquiátricos e para iniciar programas de prevenção e tratamento. Mais adiante, o autor desenvolve de maneira abrangente toda a dimensão do processo de luto. Descreve as dores, o choro, a procura, as imagens do morto e as distorções na percepção do enlutado. Apresenta também a discussão do aparecimento dos sonhos de enlutamento, do entorpecimento, dos mecanismos de evitação da perda, do esquecimento seletivo, e o surgimento dos movimentos de aproximação e afastamento. Aborda também os sentimentos que envolvem raiva e culpa, as manifestações de protesto, amargura e de autoacusação. Essa parte é finalizada com a discussão sobre a recuperação do processo de luto, apresentando a obtenção de uma nova identidade do enlutado. Discute as transições psicossociais por que passa o enlutado, as mudanças de concepções, a reorganização e a mudança nos papéis familiares.

Um capítulo importante é dedicado ao Luto Atípico, em que o autor levanta a discussão a respeito das pessoas enlutadas que "desmontam" após uma perda e são encaminhadas para atendimento psiquiátrico. Aponta para as formas apresentadas no luto crônico, as formas do luto adiado, os ataques de ansiedade e de pânico, as auto-acusações, e o surgimento de sintomas somáticos. Os três capítulos seguintes destinam-se a uma ampla descrição dos Determinantes do luto. Inicialmente,
Parkes discute o envolvimento do enlutado com o morto, ressaltando a força e a segurança do apego, a confiança e as circunstâncias de uma relação particular. Em seguida, o autor traz um estudo detalhado da relação entre o processo de luto e o tipo de morte. Levanta a discussão a respeito das mortes naturais em contrapartida às mortes inesperadas, violentas ou múltiplas. Apresenta também uma categoria de luto que causa problemas especiais, como o luto não autorizado, que designa perdas que não podem ser abertamente apresentadas. Os capítulos seguintes são dedicados às possibilidades de ajudar a enlutado. Destaca o papel da família, dos amigos e os aportes da cultura nos primeiros apoios ao enlutado. Apresenta também o papel dos grupos de ajuda mútua, dos grupos de apoio, o papel dos religiosos, o papel da equipe médica e chega à assistência especializada do luto patológico.

No último capítulo, Parkes considera em que extensão o luto pela morte de uma pessoa se assemelha às reações a outros tipos de perda, como o divórcio, o desemprego, a migração forçada, a morte de um animal de estimação, a esterilidade/ infertilidade e as perdas envolvidas na recuperação de um câncer. $\mathrm{O}$ apêndice apresenta uma seção com dados científicos e técnicos que baseiam muitas das afirmações expostas nos capítulos anteriores.

O livro de Colin Murray Parkes constitui-se então numa importante contribuição para a compreensão das situações que envolvem o luto, transmitindo de maneira clara e sensível esse inevitável processo emocional.

José Alvaro Marcolino

Setor de Psicoterapia, Departamento de Psiquiatria e Psicologia Médica da Faculdade de Ciências

Médicas da Santa Casa de São Paulo

\section{Cocaína e crack: dos fundamentos ao tratamento}

Por Marcos da Costa Leite, Arthur Guerra de Andrade e colaboradores. Porto Alegre: Editora Artes Médicas Sul Ltda. 1999. 317 páginas. ISBN 85-7307-492-2

As substâncias psicotrópicas apresentam características farmacológicas intrínsecas e extrínsecas, que determinam um perfil próprio de ação, e também uma forma peculiar de interação com o homem. Além desses aspectos relacionados à droga, existem outras dimensões de igual importância, como por exemplo, sua história e a cultura que a determina. Para o estudo do fenômeno "uso de drogas pela humanidade", é preciso que se inclua os três pontos essenciais do tripé: o encontro do homem com a substância, dentro de um certo grupo ou sistema social. A partir deste momento, ocorre uma alteração no equilí- 
brio vigente, e conseqüentemente, mudanças no padrão anterior que definirão um novo "status", muitas vezes, patológico. A fim de que se possa abordar um indivíduo que usa, abusa ou está dependente de cocaína, utilizando-se uma proposta mais eficaz, é necessário que sejam consideradas todas essas questões. Afinal, o uso de drogas pelo homem é definido hoje pela maioria dos estudiosos da área como mais um fenômeno biopsicossocial.

A recente publicação "Cocaína e crack: dos fundamentos ao tratamento" cumpre um papel extremamente difícil desde o seu projeto, pois se propôs a descrever sobre a substância, a partir de seus fundamentos, percorrendo a sua história, a cultura relacionada e atualizando sua epidemiologia, incluindo a análise dos dados coletados sobre a população brasileira. Segue este complexo trabalho, pormenorizando a farmacologia e biologia da droga, abordando a toxicologia, a clínica médica, e culminando com as peculiaridades do consumo entre as mulheres, os adolescentes e sua relação com o sistema familiar.
Ainda, sem deixar de lado, aspectos relevantes como sua interface com a Síndrome de Imunodeficiência Adquirida e outros transtornos psiquiátricos pré-morbidos. Esta obra finaliza com o estudo do diversificado e controvertido tópico sobre o tratamento da dependência, dando uma idéia exata de sua complexidade.

Todos os capítulos foram desenvolvidos cuidadosamente pelos colaboradores, levando em consideração que muitos dos assuntos apresentados carecem de uma verdade científica única. Assim, esta equipe de trabalho vence mais um desafio: auxiliar os técnicos que desejem adentrar no estudo da cocaína, dos fundamentos ao tratamento, contextualizando cada aspecto da droga e oferecendo uma visão multidimensional do tema. Missão cumprida!

Ana Cecilia P. Roselli Marques

Unidade de Dependência de Drogas do Departamento de Psicobsiologia da Universidade Federal de São Paulo 